\title{
A trajetória de Mário Pedrosa em suas primeiras apropriações do marxismo (1919-1931)
}

\author{
Juliana Rodrigues Alves ${ }^{1}$
}

\begin{abstract}
RESUMO
Este artigo analisa criticamente a trajetória intelectual de Mário Pedrosa ao longo da década de 1920 e início da década de 1930, período em que o autor realiza suas primeiras apropriações do marxismo em busca de uma análise do Brasil. Maior ênfase é dada para "Esboço de uma análise da situação econômica e social do Brasil” (1931), texto de Pedrosa em parceria com Lívio Xavier. A identificação de um clima incipiente de difusão e desenvolvimento do marxismo no Brasil, em parte combinado com os passos incertos dos primeiros anos do Partido Comunista Brasileiro (PCB) e com as mudanças teóricas da Internacional Comunista, permite compreender as possibilidades concretas de elaboração de análises originais como a que Mário Pedrosa realiza, bem como elucidar os significados mais profundos de sua trajetória.
\end{abstract}

Palavras-chave: Mário Pedrosa; Trotskismo; Partido Comunista do Brasil (PCB); Internacional Comunista.

Mário Pedrosa's trajectory in his first appropriations of marxism (1919-1931)

\begin{abstract}
This article sought to critically understand the intellectual trajectory of Mário Pedrosa, along the 1920 s and in the early 1930s, when he made his first appropriations of marxism in order to develop an analysis of Brazil. Special emphasis is given to "Esboço de uma análise da situação econômica e social do Brasil" (1931), written by Pedrosa together with Livio Xavier. The identification of an incipient climate of the spread of marxism in Brazil, combined with the uncertain steps of the Partido Comunista do Brasil (PCB, Communist Party of Brazil)'s first years and the theoretical changes of the Communist International, allows us to understand the concrete possibilities of elaborating original marxisist analysis by Mário Pedrosa, as well as elucidating the deeper meanings of his trajectory.
\end{abstract}

Keywords: Mário Pedrosa; Trotskyism; Communist Party of Brazil (PCB); Communist International.

\section{Introdução}

O presente artigo foi escrito a partir de uma pesquisa de iniciação científica com apoio do CNPq, realizada entre 2018 e 2019. A pesquisa contou com a análise das primeiras apropriações do marxismo realizadas por Mário Pedrosa ao longo década de 1920 e início da década de 1930, em um contexto também embrionário da história do

\footnotetext{
${ }^{1}$ Graduada em Ciências Sociais pela Universidade de São Paulo (USP). Bolsista PIBIC-CNPq na pesquisa "Mário Pedrosa e Caio Prado Jr. em suas primeiras apropriações do marxismo", sob orientação do Prof. Dr. Bernardo Ricupero. São Paulo. Brasil. Contato: juu.r.alves@gmail.com.
} 
marxismo no Brasil. Assim, o estudo da gênese do pensamento marxista do autor se deu em conjunto com o estabelecimento dos diálogos com o marxismo que começava a despontar no país. São destacados principalmente os textos publicados por Mário Pedrosa em periódicos da época, além de "Esboço de uma análise da situação econômica e social do Brasil” (1931), contribuição de maior densidade feita pelo autor no período.

\section{A trajetória intelectual e política de Mário Pedrosa (1919-1931)}

A adesão de Mário Pedrosa ao marxismo e ao comunismo nos anos de 1920 conformou-se em meio ao crescimento da atividade intelectual que irradiava da Europa para o mundo, momento de erupção de diversas vanguardas culturais que influenciaram o autor ao longo do período. A influência dessas vanguardas europeias foi fundamental para a inflexão política em direção à esquerda realizada por Mário Pedrosa. Seu pai, Pedro da Cunha Pedrosa, possuía uma trajetória política de longa data, o que permitiu ao filho estar um ambiente rodeado de eventos políticos desde sua infância e adolescência, fazendo com que o nome da família circulasse na imprensa carioca por meio de manifestações de apreço social dos círculos tradicionais de poder. Como aponta Dainis Karepovs (2017, p. 37), o rompimento definitivo de Pedrosa com essa influência doméstica - e o deslocamento em direção ao comunismo - teve como um dos fatores fundamentais o contato com o surrealismo europeu e a revista Clarté.

A Clarté surgiu na França em novembro de 1921 como principal expoente de um movimento que agregava principalmente manifestantes pacifistas e humanistas, entre os quais se encontrava Romain Rolland, intelectual que exerceu grande influência sobre Pedrosa no início dos anos 1920. Ao longo da década, a revista, progressivamente, converteu-se aos ideais comunistas baseando-se, a partir de 1926, nos quatro primeiros congressos da III Internacional (IC). É também nesse momento que se estabelece a ligação entre o movimento surrealista e a revista.

Já em 1927, a Clarté começa a defender as posições da Oposição de Esquerda russa, associando-se definitivamente ao trotskismo a partir de 1928, quando passa a se chamar-se La Lutte de Classes. Pedrosa acompanhou assiduamente os debates travados pela revista e, como menciona Karepovs, "não é ocioso destacar que não é mera 
coincidência que a trajetória política de Mário Pedrosa, obviamente não com a mesma cronologia, é espelhada à de Clarté, passando do comunismo, pelo surrealismo, ao trotskismo" (KAREPOVS, 2017, p. 39). Otília Arantes (2004, p. 14) também identifica no contato com os surrealistas um importante passo na trajetória de Pedrosa, destacando a viagem do autor a Europa em 1928, onde conheceu pessoalmente Pierre Naville, Louis Aragon e André Breton.

Além da influência exercida pela Clarté, destaca-se a importância da Faculdade de Direito do Rio de Janeiro - instituição frequentada por Pedrosa entre 1919 e 1923 para a conformação da trajetória do autor. Foi no curso de Direito que conheceu o professor Castro Rebello, em torno do qual alguns estudantes se agrupavam, debatendo questões de cunho social e político. Alguns anos mais tarde, quando procurado pelo PCB, Pedrosa escreve, em carta para Lívio Xavier, que suspeitava ter sido o professor Rebello quem o indicou ao Partido (PEDROSA, 1925a).

A adesão de Pedrosa ao PCB será, portanto, resultado de uma inflexão política realizada no início da década de 1920, momento em que a atuação do Partido e o desenvolvimento das interpretações da III Internacional consolidam-se como elementos contextuais importantes. Assim, cabe mencionar os principais debates travados pelo órgão e pela Internacional nesse momento.

De maneira geral, e especialmente em seus primeiros anos, a preocupação da Internacional Comunista concentrava-se nas tarefas de incentivo à revolução nos países europeus, encarados como lugares a partir de onde a revolução se espalharia. $O$ primeiro momento de diálogo direto da Internacional com a América Latina aconteceu em seu II Congresso Mundial, em 1920, em que maior atenção foi dada para o problema da revolução nos chamados países "coloniais e semicoloniais". As teses finais desse congresso preconizaram a conjugação da luta dos movimentos de libertação nacional nos países coloniais e semicoloniais à luta da classe operária dos demais países, em direção à derrota do capitalismo. Assim, nos países atrasados os movimentos burgueses de libertação nacional deveriam ser apoiados pela IC e pela classe operária, na medida em que representassem interesses genuinamente revolucionários. O caráter dessa aliança, no entanto, assume formas ambíguas. Ao mesmo tempo em que se reconhece a colaboração entre comunistas e burguesia nacional, adverte-se para que o movimento 
operário não deixe de lutar contra os democratas-burgueses pela hegemonia e independência política na revolução (Teses do II Congresso da Internacional Comunista, 1973, p. 152-156).

Além das teses acerca das questões nacional e colonial, o II Congresso foi também o responsável por consolidar a cisão entre comunistas e anarquistas ou socialdemocratas, numa política que ficou conhecida como "estratégia ofensiva a curto prazo", marcada pelas "21 condições para admissão de um partido comunista à IC". A ofensiva em direção à social-democracia foi resultado da avaliação da IC a respeito do progresso da Revolução Mundial: apesar das fortes crises do capitalismo e dos processos revolucionários em curso na Europa, a marcha da revolução estaria sendo atrasada pela cooptação de quadros importantes da classe operária pelos partidos social-democratas (ZAIDAN FILHO, 1988, p. 45).

A adesão às “21 condições” por parte do PCB se deu já em seu primeiro congresso, em 1922. Essa anuência, bem como a busca pelo reconhecimento da Internacional, indica a toada dos primeiros anos do Partido, marcados por uma tentativa (por vezes incerta e sinuosa) de firmar uma identidade política e teórica que o diferenciasse do ideário anarquista que fazia parte da história de muitos de seus militantes (ROIO, 2003, p. 73). A cisão com os movimentos social-democratas e anarquistas permanecerá no horizonte do PCB, determinando uma atitude divisionista no seio do movimento operário brasileiro, afastando, por vezes, os próprios comunistas de núcleos importantes do movimento sindical. Paradoxalmente, o forte sectarismo resultante dessa política conviveria, durante a década de 1920, com a política de "frente única”, preconizada pela IC a partir de seu III Congresso, em 1921.

Em 1921, o cenário internacional coloca novos desafios para os dirigentes da IC, isto é, se a revolução no Ocidente não se concretizasse, os comunistas precisariam lidar com a contradição imediata que a conjuntura os apresentava: como adequar a própria existência da IC e os esquemas teóricos propostos até então com o contexto de refreada da revolução mundial? Nesse sentido, as teses do III Congresso da IC passaram a orientar os comunistas para a conquista das grandes massas operárias, disputando espaço com as tendências reformistas que haviam crescido nos últimos anos. Dessa maneira, a luta contra a socialdemocracia sofreria uma mudança tática: os comunistas deveriam 
penetrar nos espaços dominados por ela para, assim, aumentar sua influência entre a classe operária. A estratégia indicada para a realização dessa nova tarefa passava a ser a construção de uma "frente única" que unisse os operários - fossem eles comunistas, socialistas ou social-democratas - contra a ofensiva do capitalismo (PINHEIRO, 1991, p. 49).

Quando, em 1924, durante o V Congresso da IC, o PCB conseguiu sua filiação oficial à Internacional, o movimento comunista estava enfrentando uma nova radicalização no que diz respeito à relação com a social-democracia, que passava a ser identificada como uma ala moderada do fascismo. Ao mesmo tempo, contudo, essa radicalização precisava ser conciliada com a tática de frente única, gerando a política que ficou conhecida como "frente única nas bases" (PINHEIRO, 1991, p. 6o).

As teses desenvolvidas pela IC foram absorvidas de maneira difusa nos primeiros anos do PCB. Nesse primeiro período, a Internacional não exercia ainda um controle direto sobre as demais seções nacionais, funcionando mais como um centro de orientação. O PCB, por sua vez, lutava para organizar suas bases em meio à clandestinidade, adequando-se precariamente às viradas teóricas dos Congressos mundiais. De alguma maneira, o Partido foi capaz de incorporar a cisão com a socialdemocracia, nos termos do II Congresso, não sem, no entanto, distanciar-se das bases sindicais, comprometendo, na prática, a tática de frente única. As idas e vindas da Internacional, bem como a imaturidade política do PCB, geraram interpretações contraditórias e políticas imprecisas, que mais tarde culminaram em uma série de mal entendidos.

Quando Mário Pedrosa entrou para o PCB, em setembro de 1925, o Partido havia acabado de realizar o seu II Congresso, em que foram produzidas teses importantes que permaneceriam no horizonte da organização nos anos seguintes. No que se refere à situação nacional, as teses aprovadas pelo Congresso baseavam-se na concepção dualista agrarismo-industrialismo, que identificava, na oposição entre o capitalismo agrário semifeudal e o capitalismo industrial moderno, a principal contradição da sociedade brasileira (PEREIRA, 2012, p. 94).

Essa concepção era dominante entre a direção do Partido e cabe destacar a influência exercida por Octávio Brandão, autor de "Agrarismo e industrialismo", que 
apenas seria publicado em 1926, porém havia sido escrito entre 1924 e 1925. Nele, Brandão utilizou a análise da luta de classes combinada às relações políticas internacionais para caracterizar a economia brasileira dos anos 1920, concebendo-a como profundamente dependente no cenário do mercado mundial. Por meio dessa análise, o autor compreendeu que a sociedade brasileira se encontrava no centro de uma disputa imperialista por influência e dominação econômica, estando de um lado o imperialismo norte-americano, representando o industrialismo, e do outro o imperialismo inglês, representando o agrarismo. Além disso, também estava presente em no livro a caracterização do Brasil como predominantemente feudal. As teses do II Congresso do PCB também refletiam o combate às tendências representadas pela socialdemocracia - no tom dado pela Internacional - e pelos anarquistas, reforçando a cisão entre comunistas e anarquistas, característica da formação do Partido (CARONE, 1982, p. 39).

No que diz respeito à aliança com a pequena burguesia, as teses do II Congresso do PCB reconhecem o potencial progressista dessa contra a grande burguesia industrial e agrária, recomendando, no entanto, certo distanciamento político desses grupos, neutralizando-os ou cooptando-os. Evidencia-se assim a preocupação com a manutenção da autonomia do proletariado no movimento comunista, discussão também nos termos do V Congresso da IC. É esse contexto que Mário Pedrosa encontrará no Partido em 1925.

O primeiro contato de Mário Pedrosa com o PCB se deu pelo recebimento de três números do jornal “A Classe Operária”, aos quais Pedrosa respondeu com uma carta que, posteriormente, seria publicada na própria revista. Nessa carta, depois intitulada "P. S. B.”, Mário Pedrosa felicita os companheiros comunistas pela redação da revista, que classifica como "órgão legítimo dos interesses e das aspirações coletivas das vastas massas trabalhadoras do Brasil" (PEDROSA, 1925b). Em seguida, o autor faz um alerta para os perigos do reformismo:

Há, entretanto, um fato que convém salientar e sublinhar porque é característico da pequena e da média burguesia: a ilusão reformista. Nunca é demais denunciar o perigo do reformismo. Sobretudo entre nós, onde tudo ainda está por fazer. Podemos dizer, sem medo e sem erro, porque é a verdade, 
que a missão do reformismo tem sido a de salvar a sociedade burguesa da transformação social rápida (PEDROSA, 1925b).

O reformismo que Pedrosa criticava era, provavelmente, o do partido socialista de Antônio Evaristo de Moraes, pois em carta a Lívio Xavier, de 8 de julho de 1925, Mário Pedrosa relata o recebimento dos três números de "A Classe Operária” e diz: "Gostei do jornal que esculhambava o partido socialista do Carpenter e do Evaristo." (PEDROSA, 1925a). No entanto, diante do contexto exposto anteriormente, a resposta de Mário Pedrosa aos comunistas revela-se coerente com as demarcações políticas e teóricas de repúdio a tendências reformistas de caráter social-democrata. Assim, a relevância desse texto, que é provavelmente a primeira manifestação pública de Pedrosa em favor do comunismo (MARQUES NETO, 1993, p. 194), aprofunda-se quando colocada em seu contexto político. É compreensível que o tom das críticas de Pedrosa às tendências reformistas tenha chamado a atenção dos quadros dirigentes do PCB, selando sua aproximação com o Partido.

No PCB, Pedrosa inicialmente dedicou-se à edição da "Revista Proletária", que tinha como diretor o comunista Mário Grazini, então secretário do Comitê Regional de São Paulo, citado por Pedrosa como um dos primeiros contatos dentro do Partido (PEDROSA, 1925c). No único número publicado da revista, Mário Pedrosa foi responsável pela escrita de dois artigos. O primeiro deles, intitulado "Aos proletários”, dedica-se à apresentação da revista, que pretende tornar-se órgão de expressão das aspirações e interesses da classe proletária. A validade e necessidade desse órgão se explica no pressuposto do qual parte o artigo: no Brasil, a classe proletária encontra-se desorganizada, oprimida e sem consciência.

\footnotetext{
E é nesse estado de inconsciência que, infelizmente, em sua enorme maioria, até hoje tem vivido o operariado brasileiro: sem coesão, amorfo, sem uma base comum de interesses que lhe dê uma unidade concreta e lhe seja o ponto de partida para a sua atuação como coletividade, e finalmente, para tudo resumir, -- ainda inorganizado (PEDROSA, 1926a, p. 3).
}

\footnotetext{
2 No documento original, este texto foi publicado com assinatura de "A Redação". A autoria à Mário Pedrosa é atribuída por Dainis Karepovs, em KAREPOVS, 2017, p. 253.
} 
A partir desse diagnóstico, toda a argumentação gira em torno da necessidade de oferecer ao proletariado os instrumentos necessários para que esse possa se dar conta da força que possui enquanto classe. O ponto mais interessante, contudo, é a consideração feita a seguir:

O operário brasileiro, por si só, tomado cada um isoladamente, ainda na
maneira de viver e até na de sentir e de pensar é um pequeno burguês. Como,
pois, desfazer essa semelhança deprimente que subordina o proletário ao
pequeno burguês, que faz daquele um copiador servil, sem originalidade, deste,
e deste, oh irrisão, o alto tipo social em que aquele se mira, aspirando imitá-lo?
(PEDROSA, 1926a, p. 4).

Há neste trecho uma aproximação entre o proletariado politicamente inconsciente e a pequena burguesia - confluência que parte de uma caracterização do "modo de sentir e pensar" pequeno-burguês - ao espelho da tendência pequenoburguesa de vislumbrar-se como burguesia. Evidentemente, o recurso estilístico aqui empregado diz respeito a um artigo essencialmente programático, mas que não deixa, por outro lado, de oferecer uma caracterização nada favorável dessa "classe anfíbia, classe sem caráter, que vive perpetuamente a oscilar, ao léu das vicissitudes econômicas, sociais, financeiras [...]" (PEDROSA, 1926a, p. 4).

O segundo artigo escrito por Pedrosa (1926b) na "Revista Proletária" é uma homenagem a Lenin, por ocasião de seu segundo aniversário de morte. Pedrosa limitase a exaltar o líder da Revolução Russa e encorajar a continuidade do seu legado, isto é, o desenvolvimento da revolução proletária na Rússia. Para isso, reproduz os deveres leninistas pronunciados por Zinoviev após a morte de Lenin, conclamando os marxistasleninistas brasileiros a colaborar com os bolcheviques em direção à realização do objetivo comum: a revolução.

Nesse período, Pedrosa contribuiu também com dois informes para o periódico "O Internacional" sobre a greve geral de 1926 na Inglaterra. Os textos são: "A Luta de classes na Inglaterra" e "Por que foi suspensa a greve geral na Inglaterra”, publicados, respectivamente, nos números 106, de 10 de julho de 1926, e 107, de 20 de julho do mesmo ano. Nos textos, o autor condena a política dos dirigentes do Conselho Geral dos Trade 
Unions, acusando-os de capitularem frente aos interesses do governo e dos patrões, colocando fim à greve:

Muita gente pensa que a greve geral na Inglaterra terminou porque os operários quiseram. Não: hoje está provado que foi a traição dos chefes do Conselho Geral dos Trade Unions que causou a terminação da greve. É preciso que o proletariado brasileiro saiba o que se passou, para poder aproveitar a lição e não consentir que suas organizações de classe, os seus sindicatos, caiam nas mãos de homens fracos, sem consciência de classe e que tenham medo da luta (PEDROSA, 1926d).

É interessante apontar que, em “Aos proletários”, Pedrosa já havia tecido uma crítica à política dos Trade Unions do Labor Party inglês:

\begin{abstract}
Armado com essa doutrina [a ideologia comunista], a consciência de classe dos trabalhadores nunca há de se turbar com ilusões reformistas, com a estreiteza egoísta de certas doutrinas que só visam o interesse imediato como o tradeunionismo, (que nunca há de libertar o proletário do jugo capitalista) e conduzem fatalmente o trabalhador à contaminação da ideologia burguesa, apagada nele sua dignificadora origem de classe, tornando-o pequeno burguês (PEDROSA, 1926a, p. 3).
\end{abstract}

Como veremos, a crítica de Pedrosa aos dirigentes dos Trade Unions será aprofundada, no início da década de 1930, de acordo com as ideias da Oposição de Esquerda, estendendo-se à política do Comitê Anglo-Russo e, especialmente, à atuação de Stalin diante do episódio. Por ora, cabe demonstrar que, já em 1926, o autor acompanhava atentamente os acontecimentos internacionais e assumia diante deles uma postura crítica, que mais tarde o levaria à identificação com o trotskismo. Assim, a ruptura de Pedrosa com o PCB deve ser vista, de certa maneira, como a continuidade de uma postura independente pela qual o intelectual comunista sempre prezou. Como aponta Marques Neto, as cartas que Pedrosa trocou com Lívio Xavier em 1926 demonstram que:

(...) o conflito entre o intelectual e o militante já está presente. [...] De uma parte, ele não se admite fora da atividade política: "[...] Como acreditar no proletariado ocidental vendo-se o que se vê, sendo-se intelectual burguês, embora diga-se revolucionário... conservando-se fora da política”. De outra parte, não abre mão de sua independência intelectual. (MARQUES NETO, 1993, p. 195) 
Em novembro de 1927, Mário Pedrosa foi escolhido pelo PCB para ser enviado a Moscou, a fim de frequentar a Escola Leninista Internacional, curso de formação para militantes da Internacional. O intelectual comunista ficaria na Europa até 1929, nunca chegando a realmente ir para Moscou. Inicialmente, Pedrosa permaneceu em Berlim e foi ao longo dessa viagem que entrou em contato direto com os debates do Partido Comunista da União Soviética (PCUS), que nesse momento enfrentava um agravamento da tensão entre o grupo de Stalin e a Oposição de Esquerda russa. Assim, decidiu permanecer na Alemanha, militando no Partido Comunista Alemão e aderindo finalmente às propostas do grupo oposicionista. O período que Pedrosa passou na Europa foi marcado por diversas crises no movimento comunista internacional e brasileiro. Cabe mencionar, especialmente, as mudanças provocadas pelo V Congresso da Internacional Comunista.

O VI Congresso da IC, em 1928, representou uma virada tática e teórica que refletiu uma nova política para a América Latina. Nele, as teses sobre a revolução burguesa nos países coloniais e semicoloniais sofreram mudanças, especialmente em razão do fracasso da aliança entre comunistas e nacionalistas na China - movimento encorajado pela Internacional nos termos do II Congresso. A partir da percepção do fracasso da estratégia da revolução na China, a Internacional passa a compreender que os erros cometidos pelo PC chinês partiram de uma avaliação incorreta acerca do caráter essencialmente reformista dos movimentos encabeçados pela burguesia nacional (Teses do VI Congresso da Internacional Comunista, 1977, p. 209).

Além disso, o reconhecimento da ligação entre as burguesias nacionais dos países coloniais, semicoloniais e dependentes com os interesses da grande propriedade rural, por um lado, e do imperialismo norte-americano, por outro, levou a IC ao diagnóstico da incapacidade revolucionária dos movimentos nacionalistas burgueses. Dessa maneira, ela considera que o movimento comunista não deveria depositar na pequena burguesia a direção da revolução democrático-pequeno-burguesa, participando e prezando pela sua hegemonia nos movimentos anti-imperialistas e de libertação nacional (Teses do VI Congresso da Internacional Comunista, 1977, p. 218).

Por fim, com a identificação da revolução democrático-burguesa como principal tarefa dos comunistas, a IC colocava a possibilidade de que a revolução socialista nas 
colônias e semicolônias - lugares sob o jugo da dominação externa e marcados pela existência de relações feudais e pré-capitalistas - se realizasse sem que a "fase capitalista" do desenvolvimento das forças produtivas fosse necessária (Teses do VI Congresso da Internacional Comunista, 1977, p. 194).

A virada teórica da IC, em 1928, teve, portanto, como uma de suas bases, o novo tratamento dado aos movimentos social-democratas, rejeitando a tática de colaboração com as burguesias nacionais que era encorajada nos termos do II Congresso (PINHEIRO, 1991, p. 165). Parte significativa dessa radicalização pode ser compreendida pelo novo lugar que a União Soviética passou a ocupar nas análises a respeito do desenvolvimento da revolução mundial. A partir do VI Congresso, a defesa da União Soviética é marcadamente apresentada como condição necessária para a libertação dos demais países. Nesse sentido, a luta contra o imperialismo nas colônias e semicolônias é vista como braço de apoio da luta que a própria União Soviética travava contra os Estados Unidos. Esse ponto reflete, em parte, a forte crise econômica e social que o Estado soviético enfrentava desde o final da Primeira Guerra Mundial, combinada com uma crise interna do PCUS envolvendo a Oposição de Esquerda, articulada por Trotsky, e o grupo de Stálin, então secretário geral do Partido.

Uma das principais bases teóricas em que se construiu o pensamento oposicionista na União Soviética diz respeito ao caráter internacionalista da revolução. Partindo dos escritos de Marx, especialmente do "Manifesto comunista", os militantes alinhados a Trotsky compreendiam a internacionalização da revolução como ponto vital para a própria sobrevivência do Estado soviético. No contexto do isolamento internacional cada vez maior enfrentado pela Rússia soviética (MARQUES NETO, 1993, p. 36), aumenta o apelo de Trotsky pela revolução permanente e a necessidade de que o PCUS e a Internacional Comunista funcionassem como polos difusores e de apoio aos outros países.

Já Stalin, opondo-se às teses internacionalistas, entrou no debate formulando as bases do que seria a teoria do "socialismo num só país", baseada na ideia de que o desenvolvimento desigual do capitalismo justificava o desenvolvimento isolado do socialismo em cada país. 
Assim, a análise acerca da revolução mundial sofre uma mudança brusca, transformando em tarefa dos comunistas de todo o mundo a defesa da própria União Soviética em primeiro lugar: "A teoria do socialismo num só país, convertida em fundamento teórico da estratégia da Internacional Comunista, significava, em resumo, subordinar a revolução mundial - em cada uma de suas fases e episódios - às exigências da construção do socialismo na URSS” (CLAUDÍN, 2013, p. 97).

No que diz respeito ao $\mathrm{PCB}$, as teses elaboradas no VI Congresso marcaram uma inflexão na política da IC em relação ao Partido, e é nesse contexto que se dá a crise interna que culminou no fim do chamado "primeiro período" do PCB, sendo marcada pelo episódio da Oposição Sindical. A tensão se estabeleceu entre a direção do Partido, de um lado, e Joaquim Barbosa e Joaquim da Costa Pimenta, de outro, responsabilizados pelos erros na política sindical do PCB. A polêmica se alastrou entre os militantes do Partido e Joaquim Barbosa conseguiu reunir em torno de si um grupo oposicionista que viria a compor a primeira grande cisão do PCB (ROIO, 1990, pp. 47-51). Esse episódio é de extrema importância se levarmos em conta que entre os dissidentes encontravam-se militantes que mais tarde entraram para o Grupo Comunista Lênin (GCL), organizado por Mário Pedrosa como braço da Oposição de Esquerda no Brasil. Cabe destacar os nomes de Rodolfo Coutinho, Lívio Xavier, Wenceslau Escobar Azambuja e Octaviano du Pin Galvão.

A crise vivida pelo movimento comunista, tanto em seu componente nacional no PCB - quanto em seu componente externo - no PCUS - conformou a saída de Pedrosa do PC brasileiro e seu alinhamento com as ideias da Oposição de Esquerda.

Em 1929, após passar um período na França, Mário Pedrosa finalmente retornou ao Brasil. Durante todos os episódios que envolveram a crise interna do PCB, o militante manteve contato com Lívio Xavier, ao mesmo tempo informando-o dos desdobramentos da Oposição de Esquerda russa (KAREPOVS, 2017, p. 48). Essa aproximação com os acontecimentos no PCB, os desdobramentos da Oposição de Esquerda no movimento comunista internacional e o período de militância no Partido Comunista Alemão e no Partido Comunista Francês forneceram a Pedrosa os elementos necessários para organizar a Oposição Brasileira. 
A adesão de Pedrosa à Oposição de Esquerda deve ser compreendida como o resultado de múltiplos fatores que se iniciam com o conhecimento das divergências políticas entre Trotsky e o grupo de Stalin no PCUS. A adesão de Pedrosa e a própria configuração da Oposição de Esquerda no Brasil deram-se, portanto, de maneira indissociável ao contexto internacional de disputa no comunismo soviético, que tem seu ápice na consolidação das ideias de Stalin e consequente expulsão de Trotsky do PCUS, em 1927, e da União Soviética, em 1928. O exílio de Trotsky, em janeiro de 1928, iniciou uma nova fase para a Oposição no mundo todo. O militante passou a dar mais atenção aos núcleos oposicionistas de outros países, fornecendo um impulso para a organização da Oposição Internacional de Esquerda (OIE). Data desse momento, por exemplo, a mudança da revista Clarté para La Lutte de Classes, demarcando sua posição oposicionista de forma mais veemente.

Como vimos, o contato do grupo de Pedrosa com as questões levantadas pela oposição por meio de publicações como a Clarté foi um fator determinante para a entrada no campo oposicionista. Essa característica revelou uma situação de independência e autonomia importante no que diz respeito à seção brasileira, bem como de outras seções nacionais, especialmente na América Latina. Ao tomar conhecimento dos debates veiculados pelas revistas de oposição, os militantes de países como o Brasil tiveram acesso a pontos de vistas diferentes sobre as discussões mais importantes, que não funcionavam como uma diretiva concreta e programática para a atuação política em seus países. Além disso, como analisou Marques Neto (1993, p. 50), o grupo brasileiro tinha um contato direto escasso, para não dizer quase nulo, com o secretariado internacional da oposição.

Por outro lado, não é possível deslocar a formação da Oposição de Esquerda Brasileira do contexto nacional, especialmente no que diz respeito ao PCB. Assim, deve estar claro que o processo de formação dessa organização teve estreita ligação com as tensões desenvolvidas no interior do Partido e se dilataram com os episódios da busca da aliança com Prestes, em 1927, com a Oposição Sindical e a cisão de 1928.

Apesar de todas as dissensões ocorridas no movimento comunista brasileiro, como descrito anteriormente, quando Pedrosa retornou ao Brasil em julho de 1929 encontrou o grupo de dissidentes do PCB desorganizados e dispersos. Sua primeira 
tarefa foi reunir os militantes em torno dos argumentos apresentados pela Oposição de Esquerda, formando um grupo de debates que pudesse homogeneizar os comunistas dispersos e heterogêneos em direção a uma opção teórica comum. Os oposicionistas brasileiros organizaram-se seguindo três questões principais: a política do comitê anglorusso; a Revolução Chinesa; e a crítica à teoria do "socialismo num só país", que teve seu contraponto na teoria da revolução permanente formulada por Trotsky em 1906 e atualizada em 1930. (MARQUES NETO, 1993, p. 51).

Os oposicionistas fundaram então, em 1930, o Grupo Comunista Lênin, primeira organização trotskista brasileira. Da mesma maneira que a Oposição Internacional de Esquerda, o GCL colocava-se como fração do PCB, buscando reorientar sua política. Imediatamente, o grupo apresentou-se ao Secretariado Internacional da Oposição de Esquerda e lançou, em 8 de maio, o jornal "A Luta de Classe”, que funcionaria como publicação oficial do órgão. Como aponta Karepovs (2017, p. 50), durante seus dez meses de duração, o GCL dedicou-se, pelas páginas de “A Luta de Classe”, a debater a orientação política do PCB, apresentar as posições da Oposição de Esquerda e, principalmente, analisar e compreender a realidade nacional. Foi durante esse período que Mário Pedrosa, junto a Lívio Xavier, escreveu "Esboço de uma análise da situação econômica e social do Brasil3", texto que consolidou as bases teóricas da Oposição brasileira. A seguir são analisados os principais pontos abordados por Pedrosa e Xavier.

Mário Pedrosa e Lívio Xavier iniciam o "Esboço de uma análise da situação econômica e social do Brasil” com uma interpretação do processo de colonização do "Novo Mundo". A argumentação dos autores evidencia a utilização da análise desenvolvida por Marx no capítulo sobre a teoria moderna da colonização presente em "O capital" (2013): diante da abundância de terras existentes nas colônias, a burguesia da metrópole se vê obrigada a produzir a dependência do trabalhador em relação ao capitalista de maneira artificial, isto é, se apropriando das terras livres de forma a

\footnotetext{
3 Este texto, datado de 12 de outubro de 1930, foi publicado no Brasil e na França, nas revistas A Luta de Classe n. 6 e La Lutte de Classes n. 28-29, respectivamente, ambas de fevereiro/março de 1931. Nesta pesquisa, optei por utilizar a versão publicada na revista brasileira, disponível para consulta no Centro de Documentação e Memória da Unesp (Cedem). Versão publicada em livro pode ser encontrada em: ABRAMO, Fúlvio; KAREPOVS, Dainis (orgs.). Na contracorrente da história: Documentos da Liga Comunista Internacionalista (1930-1933). São Paulo: Editora Brasiliense, 1987 (tradução da versão em francês por Fúlvio Abramo).
} 
introduzir a propriedade privada. Como Marx (2013, pp. 835-844), é dessa maneira que Pedrosa e Xavier descrevem a “colonização sistemática” (1931, p. 3).

No Brasil, esse processo artificial de colonização primitiva foi coroado, para os autores, com a abolição da escravidão, responsável por transformar o escravo em assalariado do campo e abastecer o mercado de trabalho de mão de obra livre para a indústria cafeeira. Em nota de rodapé, desenvolvem uma interessante formulação no sentido de que a abolição da escravidão é vista como "expressão jurídica de um processo econômico de que podemos compreender claramente a evolução, a partir de 1884, época em que a imigração aumentou progressivamente, apoiada em abundantes subsídios dados pelo Império." (PEDROSA; XAVIER, 1931, p. 3). Evidencia-se, nessa passagem, uma interpretação de cunho marcadamente materialista, que identifica na Abolição a expressão política de uma mudança de base econômica.

O resultado da implantação deste modelo colonial é apontado com clareza: diante da inexistência de terras livres e da exploração de mão de obra escrava, o Brasil constitui-se numa vasta exploração agrícola cujo produto destina-se aos mercados externos. Assim, Pedrosa e Xavier identificam, na formação colonial brasileira, uma "forma peculiar de feudalismo", que se destaca por sua particularidade em relação às demais colônias da América Latina, onde a inexistência de agricultura organizada levou à luta contra o monopólio espanhol. A caracterização da formação econômica brasileira no período colonial como um feudalismo peculiar dialoga com as interpretações da III Internacional e do PCB. Mesmo que Pedrosa e Xavier afastem-se enfaticamente dessas formulações, questionando a identificação absoluta do esquema feudal para o Brasil, é evidente que a analogia com o desenvolvimento europeu encontra ecos em pontos frágeis do texto.

No entanto, o pequeno texto não deixa de fazer alguns apontamentos pioneiros, identificando no caráter exportador e agrícola da economia colonial a fonte de uma formação social e política de caráter particular, em que o processo de desenvolvimento do capitalismo se alimenta da abolição da escravidão para proclamar burgueses, os grandes latifundiários. Pedrosa e Xavier identificam no desenvolvimento da agricultura cafeeira o próprio desenvolvimento capitalista no Brasil, resultado do esgotamento do sistema colonial de base escravocrata. 
Os autores realizam, portanto, um duplo movimento. A predominância da grande exploração rural baseada na mão de obra escrava caracteriza um sistema colonial de caráter exportador. Por sua vez, o tipo de exploração determinará as bases do desenvolvimento capitalista implementadas pela economia cafeeira, marcada também pela grande produção e, na palavra dos autores, "dependente, desde o seu começo, do mercado mundial". A partir dessa análise, a República brasileira é vista como resultado do esgotamento do sistema social e econômico baseado na exploração de mão de obra escrava. A substituição dos escravizados pelo imigrante, por sua vez, caracteriza a base da acumulação primitiva no país.

Para particularizar a burguesia brasileira, ou autores partem de uma análise sobre o caráter econômico brasileiro, que culmina em uma interpretação original da presença imperialista. Se os esquemas interpretativos do PCB se restringiam à oposição entre a burguesia industrial e agrária - divididas com base nos interesses imperialistas a que respondiam -, Pedrosa e Xavier, de outro modo, partem do pressuposto de que a atividade econômica brasileira, desde o período colonial, sempre esteve voltada ao mercado externo: "A burguesia brasileira nasceu no campo, não na cidade. A produção agrícola colonial foi destinada desde o começo aos mercados externos" (PEDROSA; XAVIER, 1931, p. 3).

Assim, sem negar a penetração crescente do imperialismo no país, os autores encontram a justificativa para a dependência econômica brasileira na gênese de sua formação colonial. Nesse cenário, o imperialismo é apresentado antes como consequência da constituição econômica e social do país do que como causa. Essa afirmação não deve, contudo, ser compreendida à maneira de uma relação causal. $\mathrm{O}$ argumento mobilizado pelos autores é, essencialmente, dialético, relacionando as condições externas do capitalismo com as alterações na base econômica nacional e encontrando nestas últimas as possibilidades para as primeiras. A partir dessa compreensão do imperialismo, é identificada a incapacidade revolucionária das burguesias nacionais:

O imperialismo altera constantemente a estrutura econômica dos países coloniais e dependentes, e impede que o desenvolvimento capitalista se processe normalmente, não permitindo que esse desenvolvimento se faça 
formalmente dentro dos limites do Estado. A burguesia nacional desses países não tem por isso uma base econômica estável para construir uma superestrutura política e social progressiva (PEDROSA; XAVIER, 1931, p. 3 ).

Portanto, incapaz de desenvolver sua autonomia política frente ao imperialismo, a burguesia nacional assume um caráter reacionário, recorrendo à defesa de governos fortes e à negação do liberalismo como forma de defender a si própria. Evidentemente, qualquer concepção teórica que condicione a revolução democráticoburguesa, em países como o Brasil, à ação das burguesias nacionais não encontra respaldo na análise de Pedrosa e Xavier.

Como consequência do desenvolvimento do capitalismo nessas condições, o Estado assume papel essencial no aprofundamento da industrialização: “a indústria nasce ligada ao Estado pelo cordão umbilical” (PEDROSA; XAVIER, 1931, p. 3). Essa característica se chocará de frente com a forma federativa do Estado: ao mesmo tempo em que o avanço do capitalismo depende da centralização do poder no Executivo, a forma política federativa leva as frações burguesas de cada estado a perseguirem interesses imediatos, desvinculados de seus interesses de classe.

É a partir dessa chave que a disputa de 1930 será compreendida. A burguesia paulista consolidou-se na medida em que se aprofundou o desenvolvimento capitalista baseado na centralização. Tal desenvolvimento capitalista, no entanto, se expandiu para outros estados, fazendo com que "as situações dominantes nesses estados queiram participar cada vez mais, em pé de igualdade, do aparelho do governo central” (PEDROSA; XAVIER, 1931, p. 3). Assim, a Revolução de 1930 é compreendida como expressão máxima da contradição entre centralização e federação na formação brasileira. É importante ressaltar, no entanto, que o texto foi redigido antes da explosão da revolta em outubro de 1930, revelando a percepção aguçada dos autores, que preveem as principais motivações políticas que levariam ao conflito.

Cabe lembrar que, seguindo o esquema interpretativo da Internacional Comunista, as principais análises sobre a Revolução de 1930 desenvolvidas no interior do PCB identificaram o conflito como resultado da disputa entre o imperialismo inglês - representado pelo Partido Republicano Paulista (PRP) e Washington Luís - e o imperialismo norte-americano - representado pela Aliança Liberal. Assim, a 
interpretação de Pedrosa e Xavier destaca-se por superar a concepção essencialmente dualista do PCB e da Internacional, negando a disputa esquemática entre o imperialismo inglês e o norte-americano. Além disso, como aponta Marques Neto (1993), a visão dos trotskistas a respeito da revolução teve diversos pontos incorporados pela literatura especializada dos anos posteriores, consolidando-se como uma das mais correntes na produção acadêmica sobre o tema.

Por fim, cabe dizer que ao longo da argumentação desenvolvida por Pedrosa e Xavier evidencia-se o arcabouço teórico trotskista: as análises acerca do desenvolvimento do capitalismo nos estados brasileiros ecoam a teoria do desenvolvimento desigual e combinado de Trotsky, além da retomada de alguns argumentos do líder oposicionista sobre a Rússia czarista (KAREPOVS; MARQUES NETO, 2007, p. 246). Além disso, Pedrosa e Xavier citam "O 18 brumário de Luís Bonaparte" (2011), de Marx, incorporando a análise de frações de classe como pontochave da sua interpretação.

\section{Considerações finais}

A análise mobilizada anteriormente teve como objetivo esclarecer o contexto político e social em que Mário Pedrosa realizou suas primeiras apropriações do marxismo, permitindo a identificação dos significados, diálogos e particularidades da produção acadêmica do autor no período que compreende a década de 1920 e início de 1930. Nesse sentido, "Esboço de uma análise da situação econômica e social do Brasil” foi mobilizado como exemplo da consolidação do marxismo enquanto opção teórica e política na trajetória do autor.

No que diz respeito ao cenário geral, a reconstrução do panorama histórico permitiu a definição do clima ainda incipiente de difusão do marxismo no Brasil no período em questão. Em grande parte determinado pelos passos incertos dos primeiros anos do Partido Comunista Brasil, o quadro teórico identificado como marxista é, nesse período, amplo e impreciso. Nesse contexto, a tentativa pioneira de interpretação marxista da realidade brasileira realizada por Octávio Brandão foi, sem demora, assimilada pelo PCB, figurando como base teórica de seus primeiros anos e, de certa 
forma, estabelecendo os limites dos exames a serem realizados pelos comunistas a partir de então. De certa maneira, esse ambiente engendrou as possibilidades concretas de elaboração de análises marxistas originais por Mário Pedrosa. Por outro lado, a flexibilidade encontrada por Pedrosa no seio do movimento comunista foi acentuada pelo distanciamento da Internacional Comunista, que em seus primeiros anos concentrou-se nos países que compunham o centro do mundo, relegando à América Latina uma atenção imprecisa.

Em conclusão, no que diz respeito aos significados particulares de "Esboço..." na trajetória de Mário Pedrosa, é importante mencionar que, ao mesmo tempo em que o texto inicia uma tradição teórica que será seguida pelas vertentes trotskistas após 1931, ele foi uma das últimas contribuições intelectuais de Pedrosa na primeira fase de sua carreira. Isso porque a partir de 1933 se dedicará à crítica de arte, sem, no entanto, se desligar da militância política.

\section{Referências}

ABRAMO, Fúlvio; KAREPOVS, Dainis (Orgs.). Na contracorrente da história: documentos da Liga Comunista Internacionalista (1930-1933). São Paulo: Editora Brasiliense, 1987.

ARANTES, Otília B. F. Mário Pedrosa: itinerário crítico. São Paulo: Cosac Naify, 2004.

CLAUDÍN, Fernando. A crise do movimento comunista. São Paulo: Expressão Popular, 2013.

INTERNACIONAL COMUNISTA. Segundo Congreso: tesis y adiciones sobre los problemas nacional y colonial. In: Los Cuatro Primeros Congresos de La Internacional Comunista. Argentina: Cuadernos Pasado y Presente, n. 43, 1. ed., 1973.

Tesis sobre el movimiento revolucionario en las colonias y semicolonias. In: VI Congreso de la Internacional Comunista. México: Cuadernos Pasado y Presente, n. 66,1977 .

KAREPOVS, Dainis. Pas de politique mariô! Mário Pedrosa e a política. São Paulo: Ateliê Editorial/Fundação Perseu Abramo, 2017.

; MARQUES NETO, José Castilho. Os trotskistas brasileiros e suas organizações políticas (1930-1966). In: RIDENTI, Marcelo; REIS, Daniel Aarão (Orgs.). História do 
marxismo no Brasil: partidos e organizações dos anos 1920 aos 196o. São Paulo: Editora da Unicamp, 2007. Vol. 5 .

MARQUES NETO, José Castilho. Solidão revolucionária: Mário Pedrosa e as origens do trotskismo no Brasil. Rio de Janeiro: Paz e Terra, 1993.

MARX, Karl. O capital: crítica da economia política. São Paulo: Boitempo, 2013. Livro I.

PARTIDO COMUNISTA DO BRASIL. O II Congresso do P.C.B. Informe republicado pelo PCB no periódico Classe Operária, ano I, n. 11, 8 maio 1946. Ver reprodução em: CARONE, Edgar. O P.C.B. (1922 a 1943). São Paulo: Editora Difel, 1982. Vol. 1. Coleção Corpo e Alma do Brasil.

PEREIRA, Astrojildo. Formação do PCB (1922-1928). São Paulo: Fundação Maurício Grabois e Anita Garibaldi, 2012.

PINHEIRO, Paulo Sérgio. Estratégias da ilusão: a revolução mundial e o Brasil (1922 1935). São Paulo: Companhia das Letras, 1991.

ROIO, Marcos Del. O impacto da Revolução Russa e da Internacional Comunista no Brasil. In: MORAES, João Quartim de; REIS, Daniel Aarão (Orgs.) História do marxismo no Brasil: o impacto das revoluções. São Paulo: Editora da Unicamp, 2003. Vol. 1.

A classe operária na revolução burguesa: a política de alianças do PCB (19281935). Belo Horizonte, 1990.

ZAIDAN FILHO, Michel. O PCB e a Internacional Comunista (1922-1929). São Paulo: Vértice, 1988.

\section{Cartas, textos e artigos de Mário Pedrosa}

Carta de Mário Pedrosa a Lívio Xavier, 29 jul. 1925c. Disponível no Centro de Documentação e Memória da Unesp (Cedem).

Carta de Mário Pedrosa a Lívio Xavier, São Paulo, 8 jul. 1925a. Original encontra-se no acervo do Centro de Documentação e Memória da Unesp (Cedem).

PEDROSA, Mário. P.S.B. Periódico A Classe Operária. Rio de Janeiro, n. 12, 18 jul. 1925b. A transcrição do texto foi gentilmente fornecida pelo Prof. Dr. Dainis Karepovs, diante da impossibilidade de localizar o documento original que se encontra no Centro de Documentação e Memória da Unesp (Cedem). 
. (assinado “A Redação”) Aos proletários. Revista Proletária. São Paulo, n. 1, 21 jan. 1926a, p. 3. O original encontra-se no Centro de Documentação e Memória da Unesp (Cedem).

(assinado com pseudônimo de Spartacus) Segundo aniversário da morte de Lenine. Revista Proletária, São Paulo, n. 1, 21 jan. 1926b, p. 6. O original encontra-se no Centro de Documentação e Memória da Unesp (Cedem).

( (assinado M.P.) A luta de classes na Inglaterra. Periódico O Internacional, São

Paulo, n. 107, 29 jul. 1926c. O original encontra-se no Centro de Documentação e Memória da Unesp (Cedem).

. (assinado M.P.) Por que foi suspensa a greve geral na Inglaterra. Periódico $O$

Internacional, São Paulo, n. 107, 29 jul. 1926d. O original encontra-se no Centro de Documentação e Memória da Unesp (Cedem).

; XAVIER; Lívio. Esboço de uma análise da situação econômica e social do Brasil. Revista A Luta de Classes, n. 6, fev./mar. 1931. O original encontra-se no Centro de Documentação e Memória da Unesp (Cedem). 